\title{
DAMPAK PENCEMARAN UDARA TERHADAP KUALITAS UDARA DI PROVINSI BALI
}

\author{
Ni Putu Decy Arwini \\ ${ }^{1}$ Program Studi Teknik Industri, Fakultas Teknik, Universitas Mahendradatta Bali \\ Jl. Ken Arok No 12, Peguyangan Denpasar Utara, Bali 80115 \\ Email: decyarwini@yahoo.co.id
}

\begin{abstract}
Abstrak - Perkembangan teknologi transportasi saat ini telah membuat jarak menjadi semakin tidak berarti, namun tanpa disadari telah terjadi suatu degradasi terhadap lingkungan sebagai dampak langsung perkembangan teknologi transportasi. Emisi gas buang yang dihasilkan oleh setiap kendaraan kini telah menjadi sumber polusi utama yaitu sekitar $70 \%$ dari seluruh faktor penyebab polusi. Secara tidak sadar bahwa selama ini kualitas udara yang dihirup oleh masyarakat secara perlahan-lahan mengalami penurunan sehingga tidak disadari hingga muncul suatu dampak yang dianggap merugikan, barulah kemudian masyarakat sadar bahwa telah terjadi masalah yang sangat pelik sebagai akibat dari transportasi yang kurang ramah lingkungan. Bahan bakar untuk transportasi hampir semuanya berasal dari olahan minyak bumi yang merupakan sumber daya alam tak terbarukan sehingga disatu pihak telah menimbulkan pencemaran udara yang sangat mempengaruhi kesehatan disamping itu juga jumlah bahan baku untuk produksi bahan bakar kendaraan ini juga semakin menipis sehingga harga yang ditetapkan untuk konsumsi masyarakat juga menjadi lebih mahal.
\end{abstract}

Tujuan dari penelitian ini antara lain adalah untuk mengetahui seberapa besar tingkat pencemaran udara di Provinsi Bali pada beberapa titik sampel sebagai akibat dari kendaraan bermotor, untuk mengetahui macam dan besarnya kandungan gas berbahaya yang dihasilkan oleh kendaraan bermotor di Provinsi Bali, untuk mengetahui dampak yang ditimbulkan oleh gas buang kendaraan tersebut terhadap kesehatan saluran pernafasan penduduk Provinsi Bali, serta cara-cara yang dapat ditempuh untuk mengurangi dampak negatif akibat dari pencemaran yang ditimbulkan oleh emisi gas buang kendaraan.

Kata kunci: Pencemaran udara, transportasi, gangguan pada saluran pernafasan, emisi gas buang kendaraan, sampel, laboratorium.

\begin{abstract}
The development of transportation technology now has made distance become increasingly meaningless, but without realizing there has been a degradation of the environment as a direct impact of the development of transportation technology. Exhaust emissions produced by each vehicle have now become the main source of pollution, which is about $70 \%$ of all factors causing pollution. Unconsciously that so far the air quality that is inhaled by the community has slowly decreased so that it is not realized until an adverse impact appears, then the community then realizes that there has been a very complicated problem as a result of transportation that is less environmentally friendly. Most of the fuel for transportation comes from refined petroleum which is a non-renewable natural resource so that on the one hand it has caused air pollution which greatly affects health besides the amount of raw material for fuel production of these vehicles is also running low so prices are set for consumption society also becomes more expensive.

The purpose of this research is to find out how much the level of air pollution in Bali Province at several sample points as a result of motor vehicles, to find out the type and amount of hazardous gas content produced by motor vehicles in Bali Province, to determine the impact caused by the exhaust gas of the vehicle on the health of the respiratory tract of residents of the Province of Bali, as well as ways that can be taken to reduce the negative impact resulting from pollution caused by vehicle exhaust emissions.
\end{abstract}

Keyword: air pollution, transportation, gas emission, sample, and laboratory. 


\section{PENDAHULUAN}

Perkembangan teknologi transportasi saat ini telah membuat jarak menjadi semakin tidak berarti. Dalam waktu singkat jarak antar benua dapat ditempuh dalam hitungan jam, padahal sekitar seabad yang lalu hal seperti ini masih merupakan suatu yang sulit untuk diwujudkan. Kendaraan bermotor semakin canggih dalam menaklukkan alam dan juga semakin nyaman untuk dikendarai. Industri angkutan umumpun mengalami perkembangan yang cukup signifikan. Mulai dari pesawat udara, kereta baik itu MRT maupun LRT dan bus angkutan umum semuanya mengalami kemajuan teknologi baik dari segi kecepatan, kenyamanan maupun ekonomi.

Namun dibalik itu, terjadi suatu degradasi terhadap lingkungan sebagai dampak langsung perkembangan teknologi transportasi. Emisi gas buang yang dihasilkan oleh setiap kendaraan kini telah menjadi sumber polusi utama yaitu sekitar $70 \%$ dari seluruh faktor penyebab polusi. Secara tidak sadar bahwa selama ini kualitas udara yang dihirup oleh masyarakat secara perlahan-lahan mengalami penurunan sehingga tidak disadari hingga muncul suatu dampak yang dianggap merugikan, barulah kemudian masyarakat sadar bahwa telah terjadi masalah yang sangat pelik sebagai akibat dari transportasi yang kurang ramah lingkungan.

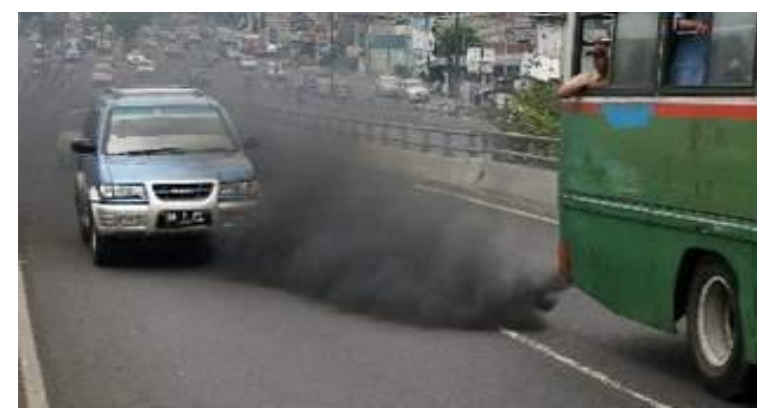

Gambar 1.1 Pencemaran Udara Akibat Emisi Gas Buang Kendaraan

Bahan bakar untuk transportasi hampir semuanya berasal dari olahan minyak bumi yang merupakan sumber daya alam tak terbarukan sehingga disatu pihak telah menimbulkan pencemaran udara yang sangat mempengaruhi kesehatan, disamping itu juga jumlah bahan baku untuk produksi bahan bakar kendaraan ini juga semakin menipis sehingga harga yang ditetapkan untuk konsumsi masyarakat juga menjadi lebih mahal.

\section{KAJIAN PUSTAKA \\ Pencemaran Udara}

Setiap kendaraan

yang

menggunakan bahan bakar minyak sebagai tenaga penggerak pasti akan menghasilkan emisi gas buang sebagai hasil akhir. Emisi gas buang kendaraan ini merupakan kontributor utama pencemaran udara yang terjadi saat ini. Pencemaran udara dapat di definisikan sebagai kehadiran satu atau lebih substansi fisik, kimia, atau biologi di atmosfer dalam jumlah yang dapat membahayakan kesehatan manusia, hewan, dan tumbuhan, mengganggu estetika dan kenyamanan atau merusak properti. Beberapa definisi gangguan fisik seperti polusi suara, panas, radiasi, atau polusi cahaya dianggap sebagai polusi udara. Gas-gas yang terkandung dalam emisi gas buang kendaraan inilah yang membahayakan kesehatan manusia terutama kesehatan saluran pernafasan.

Definisi lain menyebutkan bahwa pencemaran udara adalah bertambahnya bahan atau substrat fisik atau kimia kedalam lingkungan udara normal yang mencapai jumlah tertentu sehingga dapat dideteksi (dihitung atau diukur) oleh manusia serta memberikan dampak pada manusia, binatang, maupun tumbuhan (Mukono, 1997).

Secara umum, pencemar udara dapat dibedakan menjadi dua yaitu pencemar primer dan pencemar sekunder. Pencemar primer adalah substansi pencemar yang ditimbulkan langsung dari sumber pencemaran udara. Karbonmonoksida adalah sebuah contoh dari pencemar udara primer karena ia merupakan hasil dari pembakaran. Pencemar sekunder adalah substansi pencemar yang terbentuk dari reaksi pencemar-pencemar primer di atmosfer. Pembentukan ozon dalam smog fotokimia adalah sebuah contoh dari pencemaran udara sekunder.

Sumber pencemaran udara dari aktivitas manusia dapat dibedakan kedalam empat kelompok yaitu: 
1. Sumber bergerak, yaitu sumber tidak tetap pada suatu tempat yang berasal dari kendaraan bermotor,

2. Sumber bergerak spesifik, yaitu sumber tidak tetap pada suatu tempat yang berasal dari kereta api, pesawat terbang, kapal laut, dan kendaraan berat lainnya,

3. Sumber tidak bergerak, yaitu sumber emisi yang tetap pada suatu tempat,

4. Sumber tidak bergerak spesifik, yaitu sumber emisi yang tetap pada suatu tempat yang berasal dari pembakaran hutan dan pembakaran sampah (PP No 41 tahun 1999).

Udara dikatakan bersih bila memenuhi syarat tertentu. Komposisi gas yang terkandung tidak melebihi batas yang telah ditentukan. Berikut disajikan dalam bentuk tabel komposisi udara kering dan bersih (Fardiaz, 1992)

Tabel 1 Komposisi Udara Kering dan Bersih

\begin{tabular}{|llll|}
\multicolumn{1}{c}{ Komponen } & Formula & $\begin{array}{c}\text { Persen } \\
\text { Volume }\end{array}$ & \multicolumn{1}{c|}{ Ppm } \\
\hline Nitrogen & $\mathrm{N}_{2}$ & 78,08 & 780,800 \\
\hline Oksigen & $\mathrm{O}_{2}$ & 20,95 & 209,500 \\
\hline Argon & $\mathrm{Ar}$ & 0,934 & 9,340 \\
\hline Karbonmonoksida & $\mathrm{CO}_{2}$ & 0,0314 & 314 \\
\hline Neon & $\mathrm{Ne}$ & 0,00182 & 18 \\
\hline Helium & $\mathrm{He}$ & 0,000524 & 5 \\
\hline Metana & $\mathrm{CH}_{4}$ & 0,0002 & 2 \\
\hline Kripton & $\mathrm{Kr}$ & 0,000114 & 1 \\
\hline
\end{tabular}

Sumber: Fardiaz, 1992

Tabel 2 Kriteria Udara Bersih dan Udara Tercemar

\begin{tabular}{|c|c|c|c|}
\hline No & Parameter & Udara bersih & Udara tercemar \\
\hline 1 & Bahan Partikel & $0,01-0,02 \mathrm{mg} / \mathrm{m}^{3}$ & $0,07-0,7 \mathrm{mg} / \mathrm{m}^{3}$ \\
\hline 2 & $\mathrm{SO}_{2}$ & $0,003-0,02 \mathrm{ppm}$ & $0,02-2 \mathrm{ppm}$ \\
\hline 3 & $\mathrm{CO}$ & $<1 \mathrm{ppm}$ & $5-200 \mathrm{ppm}$ \\
\hline 4 & $\mathrm{NO}_{2}$ & $0,003-0,02 \mathrm{ppm}$ & $0,02-0,1 \mathrm{ppm}$ \\
\hline 5 & $\mathrm{CO}_{2}$ & $310-330 \mathrm{ppm}$ & $350-700 \mathrm{ppm}$ \\
\hline 6 & Hidrokarbon & $<1 \mathrm{ppm}$ & $1-20 \mathrm{ppm}$ \\
\hline
\end{tabular}

Sumber: Kementerian Lingkungan Hidup, 2003

Udara di alam tidak pernah bersih tanpa polutan sama sekali. Kehadiran bahan atau zat-zat asing diudara dalam jumlah tertentu dan dalam waktu yang cukup lama akan berdampak pada kehidupan manusia, tumbuhan, dan binatang. Bila keadaan itu terjadi maka udara dikatakan tercemar. seperti disajikan tabel diatas, komposisi udara yang dapat digunakan sebagai parameter tercemar tidaknya udara pada suatu daerah (Mukono, 1997).

\section{Dampak Emisi Gas Buang Kendaraan Terhadap Kesehatan}

Senyawa-senyawa di dalam gas buang terbentuk selama energi diproduksi untuk menjalankan kendaraan bermotor. Beberapa senyawa yang dinyatakan dapat membahayakan kesehatan adalah berbagai oksida sulfur, oksida nitrogen, dan oksida karbon, hidrokarbon, logam berat tertentu dan partikulat. Pembentukan gas buang tersebut terjadi selama pembakaran bahan bakar fosil-bensin dan solar didalam mesin. Dibandingkan dengan sumber stasioner seperti industri dan pusat tenaga listrik, jenis proses pembakaran yang terjadi pada mesin kendaraan bermotor tidak sesempurna di dalam industri dan menghasilkan bahan pencemar pada kadar yang lebih tinggi, terutama berbagai senyawa organik dan oksida nitrogen, sulfur dan karbon. Selain itu gas buang kendaraan bermotor juga langsung masuk ke dalam lingkungan jalan raya yang sering dekat dengan masyarakat, dibandingkan dengan gas buang dari cerobong industri yang tinggi. Dengan demikian maka masyarakat yang tinggal atau melakukan kegiatan lainnya di sekitar jalan yang padat lalu lintas kendaraan bermotor dan mereka yang berada di jalan raya seperti para pengendara bermotor, pejalan kaki, dan polisi lalu lintas, penjaja makanan sering kali terpajan oleh bahan pencemar yang kadarnya cukup tinggi. Estimasi dosis pemajanan sangat tergantung kepada tinggi rendahnya pencemar yang dikaitkan dengan kondisi lalu lintas pada saat tertentu. Keterkaitan antara pencemaran udara di perkotaan dan kemungkinan adanya resiko terhadap kesehatan, baru dibahas pada beberapa dekade belakangan ini. Pengaruh yang merugikan mulai dari meningkatnya kematian akibat adanya kabut asap sampai pada gangguan estetika dan kenyamanan. Gangguan kesehatan lain diantara kedua pengaruh yang ekstrim ini, misalnya kanker pada paru-paru atau organ tubuh lainnya, penyakit pada saluran tenggorokan yang 
bersifat akut maupun khronis, dan kondisi yang diakibatkan karena pengaruh bahan pencemar terhadap organ lain sperti paru, misalnya sistem syaraf. Karena setiap individu akan terpajan oleh banyak senyawa secara bersamaan, sering kali sangat sulit untuk menentukan senyawa mana atau kombinasi senyawa yang mana yang paling berperan memberikan pengaruh membahayakan terhadap kesehatan. Bahaya gas buang kendaraan bermotor terhadap kesehatan tergantung dari toksiats (daya racun) masing-masing senyawa dan seberapa luas masyarakat terpajan olehnya. Beberapa faktor yang berperan di dalam ketidakpastian setiap analisis resiko yang dikaitkan dengan gas buang kendaraan bermotor antara lain adalah :

1. Definisi tentang bahaya terhadap kesehatan yang digunakan

2. Relevansi dan interpretasi hasil studi epidemiologi dan eksperimental

3. Realibilitas dari data pajanan

4. Jumlah manusia yang terpajan

5. Keputusan untuk menentukan kelompok resiko yang mana yang akan dilindungi

6. Interaksi antara berbagai senayawa di dalam gas buang, baik yang sejenis maupun antara yang tidak sejenis

7. Lamanya terpajan (jangka panjang atau pendek)

Pada umumnya istilah dari bahaya terhadap kesehatan yang digunakan adalah pengaruh bahan pencemar yang dapat menyebabkan meningkatnya resiko atau penyakit atau kondisi medik lainnya pada seseorang ataupun kelompok orang. Pengaruh ini tidak dibatasi hanya pada pengaruhnya terhadap penyakit yang dapat dibuktikan secara klinik saja, tetapi juga pada pengaruh yang pada suatu mungkin juga dipengaruhi faktor lainnya seperti umur misalnya. Telah banyak bukti bahwa anakanak dan para lanjut usia merupakan kelompok yang mempunyai resiko tinggi di dalam peristiwa pencemaran udara. Anakanak lebih peka terhadap infeksi saluran pernafasan dibandingkan dengan orang dewasa, dan fungsi paru-paru nya juga berbeda. Para usia lanjut masuk di dalam kategori kelompok resiko tinggi karena penyesuaian kapasitas dan fungsi paruparu menurun, dan pertahanan imunitasnya melemah. Karena kapasitas paru-paru dari penderita penyakit jantung dan paru-paru juga rendah, kelompok ini juga sangat peka terhadap pencemaran udara. Berdasarkan sifat kimia dan perilakunya di lingkungan, dampak bahan pencemar yang terkandung di dalam gas buang kendaraan bermotor digolongkan sebagai berikut:

1. Bahan-bahan pencemar yang terutama mengganggu saluran pernafasan. Yang termasuk dalam golongan ini adalah oksida sulfur, partikulat, oksida nitrogen, ozon dan oksida lainnya.

2. Bahan-bahan pencemar yang menimbulkan pengaruh racun sistemik, seperti hidrokarbon monoksida dan timbel/timah hitam.

3. Bahan-bahan pencemar yang dicurigai menimbulkan kanker seperti hidrokarbon.

4. Kondisi yang mengganggu kenyamanan seperti kebisingan, debu jalanan, dana in sebagainya

\section{Pencemaran Udara Sebagai Akibat dari Emisi Gas Buang Kendaraan}

Polusi udara dari kendaraan bermotor bensin menurut data Kementerian Lingkungan Hidup menyumbang 70\% karbon monoksida (CO), 100\% plumbum $(\mathrm{Pb}), 60 \%$ hidrokarbon $(\mathrm{HC})$, dan $60 \%$ oksida nitrogen (NOx).

Tabel 3 Prosentase gas yang dihasilkan berdasarkan jenis BBM yang digunakan

\begin{tabular}{|lcc}
\multicolumn{1}{|c}{ Jenis Gas Buang } & \multicolumn{2}{c}{ Kontribusi Berdasarkan Jenis BBM } \\
\cline { 2 - 3 } & Bensin (\%) & Solar (\%) \\
\hline Karbonmonoksida (CO) & 89 & 11 \\
\hline Hidrokarbon (HC) & 73 & 27 \\
\hline Nitrogen Dioksida $\left(\mathbf{N O}_{\mathbf{x}}\right)$ & 61 & 39 \\
\hline Sulfur Dioksida $\left(\mathbf{S O}_{2}\right)$ & 15 & 85 \\
\hline Karbon Dioksida $\left(\mathbf{C O}_{2}\right)$ & 53 & 0 \\
\hline Timbal $(\mathbf{P b})$ & 100 & 99 \\
\hline Asap & 1 & \\
\hline
\end{tabular}

Sumber: Kementerian Lingkungan Hidup, 2003

Pengukuran kualitas udara oleh Kementerian Lingkungan Hidup 
menunjukkan kualitas udara enam kota besar, yaitu Jakarta, Surabaya, Bandung, Medan, Jambi, dan Pekan Baru hanya menunjukkan kondisi baik selama $22-62$ hari setahun. Kualitas udara ditentukan dalam standar ISPU (Indeks Standar Pencemaran Udara), disebutkan kategori "baik" jika tingkat kualitas udara tidak memberikan efek buruk bagi kesehatan manusia serta tidak berpengaruh pada tumbuhan dan nilai estetika bangunan.

Jenis bahan bakar yang digunakan oleh kendaraan juga berpengaruh terhadap emisi gas buang yang dihasilkan. seperti disajikan tabel 3 diatas, mengenai prosentase masing-masing gas yang dihasilkan oleh bahan bakar minyak yang digunakan.

Gas yang terkandung dalam emisi gas buang kendaraan antara lain karbonmonoksida, oksida nitrogen, oksida sulfur, CFC, hidrokarbon, ozon dan plumbum. Berikut dibahas dengan lebih detail beberapa diantaranya:

a. Karbonmonoksida

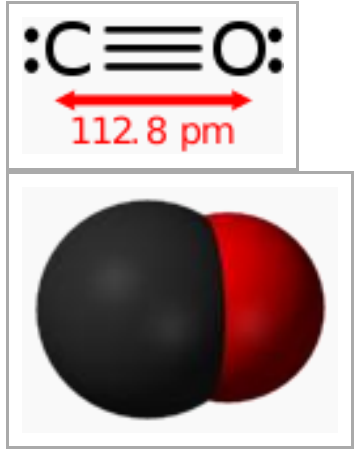

Gambar 2.1 Rantai Karbon CO

Gas ini terdiri dari unsur karbon dan oksigen, dengan rumus kimia $\mathrm{CO}$. Gas ini juga tidak berbau, tidak berwarna, tidak berasa dan sangat mudah terbakar. Karbon monoksida dihasilkan dari pembakaran tak sempurna dari senyawa karbon, sering terjadi pada mesin pembakaran dalam. Karbon monoksida terbentuk apabila terdapat kekurangan oksigen dalam proses pembakaran. Karbon dioksida mudah terbakar dan menghasilkan lidah api berwarna biru, menghasilkan karbon dioksida.
Walaupun ia bersifat racun, $\mathrm{CO}$ memainkan peran yang penting dalam teknologi modern, yakni merupakan prekursor banyak senyawa karbon

b. Gas Klorofluorokarbon (CFC)

Ancaman yang diketahui terhadap keseimbangan ozon adalah klorofluorokarbon (CFC) yang merupakan gas buatan manusia yang dapat menimbulkan penipisan ozon dan menyebabkan penurunan tingkat ozon global secara berangsur-angsur. CFC dimanfaatkan oleh masyarakat modern misalnya sebagai bahan pendingin dalam kulkas, sprayer, pembuatan busa dan bahan pelarut terutama bagi kilang-kilang elektronik. Masa hidup CFC cukup panjang, 1 molekul yang dibebaskan hari ini bisa ada 50 hingga 100 tahun dalam atmosfer sebelum dapat diuraikan. Dalam waktu kira-kira 5 tahun, CFC bergerak naik dengan perlahan ke dalam stratosfer $(10-50$ $\mathrm{km})$. Di atas lapisan ozon utama, pertengahan ketinggian $20-25 \mathrm{~km}$, sinar UV diserap oleh ozon. Molekul CFC terurai setelah bercampur dengan UV, dan membebaskan atom klorin. Atom klorin ini menyebabkan penipisan ozon dan akhirnya menjadikan lubang ozon. Lubang ozon di Antartika disebabkan oleh penipisan lapisan ozon antara ketinggian tertentu diseluruh Antartika pada musim semi. Pembentukan 'lubang' tersebut terjadi setiap bulan September dan pulih ke keadaan normal pada lewat musin semi atau awal musim panas. Dalam bulan Oktober 1987, 1989, 1990 dan 1991, lubang ozon yang luas telah dilacak di seluruh Antartika dengan peningkatan $60 \%$ dengan permukaan lubang pra-ozon. Pada bulan Oktober 1991, permukaan terendah atmosfer ozon yang pernah dicatat telah terjadi di seluruh Antartika. Spektrofotometer adalah alat yang digunakan untuk mengukur jumlah ozon. Spektrofotometer pertama diciptakan pada tahun 1920 oleh Gordon Dobson. Kini terdapat kurang lebih 80 jenis alat ini untuk digunakan di seluruh dunia dalam mengukur jumlah ozon. 
Spektrofotometer Dobson mengukur ozon dengan membandingkan jumlah penyinaran antar dua UV. Satu jarak gelombang terlacak kuat dengan ozon manakala yang satu lagi tidak. Perbedaan antara jumlah dua sinar secara langsung berhubungan dengan jumlah ozon.

c. Hidrokarbon

Dalam bidang kimia, hidrokarbon adalah sebuah senyawa yang terdiri dari unsur karbon (C) dan hidrogen $(\mathrm{H})$. Seluruh hidrokarbon memiliki rantai karbon dan atom-atom yang berikatan dengan rantai tersebut. Istilah tersebut digunakan juga sebagai pengertian dari hidrokarbon alifatik. Sebagai contoh, metana (gas rawa) adalah hidrokarbon dengan satu atom karbon dan empat atom misalnya $\mathrm{CH}_{4}$. Etana adalah hidrokarbon (lebih terperinci, sebuah alkana) yang terdiri dari dua atom karbon bersatu dengan sebuah ikatan tunggal, masing-masing mengikat tiga atom karbon: $\mathrm{C}_{2} \mathrm{H}_{6}$. Propana memiliki tiga atom $\mathrm{C}\left(\mathrm{C}_{3} \mathrm{H}_{8}\right)$ dan seterusnya $\left(\mathrm{C}_{n} \mathrm{H}_{2 \cdot n+2}\right)$. Pada dasarnya terdapat tiga jenis hidrokarbon:

1. Hidrokarbon aromatik, mempunyai setidaknya satu cincin aromatik

2. Hidrokarbon jenuh, juga disebut alkana, yang tidak memiliki ikatan rangkap

3. Hidrokarbon tak jenuh, yang memiliki satu atau lebih ikatan rangkap antara atom-atom karbon, yang dibagi menjadi:

- Alkena

- Alkuna

Ozon terdiri dari tiga molekul oksigen dan amat berbahaya pada kesehatan manusia. Secara alamiah, ozon dihasilkan melalui percampuran cahaya ultraviolet dengan atmosfer bumi dan membentuk suatu lapisan ozon pada ketinggian 50 kilometer.

d. Oksida sulfur dan partikulat

Sulfur dioksida (SO2) merupakan gas buang yang larut dalam air yang langsung dapat terabsorbsi di dalam hidung dan sebagian besar saluran ke paru-paru. Karena partikulat di dalam gas buang kendaraan bermotor berukuran kecil, partikulat tersebut dapat masuk sampai ke dalam alveoli paru-paru dan bagian lain yang sempit. Partikulat gas buang kendaraan bermotor terutama terdiri jelaga (hidrokarbon yang tidak terbakar) dan senyawa anorganik (senyawa-senyawa logam, nitrat dan sulfat). Sulfur dioksida di atmosfer dapat berubah menjadi kabut asam sulfat (H2SO4) dan partikulat sulfat. Sifat iritasi terhadap saluran pernafasan, menyebabkan $\mathrm{SO} 2$ dan partikulat dapat membengkaknya 5ank are mukosa dan pembentukan mukosa dapat meningkatnya hambatan aliran udara pada saluran pernafasan. Kondisi ini akan menjadi lebih parah bagi kelompok yang peka, seperti penderita penyakit jantung atau paru-paru dan para lanjut usia.

e. Oksida Nitrogen

Diantara berbagai jenis oksida nitrogen yang ada di udara, nitrogen dioksida (NO2) merupakan gas yang paling beracun. Karena larutan NO2 dalam air yang lebih rendah dibandingkan dengan SO2, maka $\mathrm{NO} 2$ akan dapat menembus kedalam saluran pernafasan lebih dalam. Bagian dari saluran yang pertama kali dipengaruhi adalah 5ank are mukosa dan jaringan paru. Organ lain yang dapat dicapai oleh $\mathrm{NO} 2$ dari paru adalah melalui aliran darah. Karena data epidemilogi tentang resiko pengaruh NO2 terhadap kesehatan manusia sampai saat ini belum lengkap, maka evaluasinya banyak didasarkan pada hasil studi eksprimental. Berdasarkan studi menggunakan binatang percobaan, pengaruh yang membahayakan seperti misalnya meningkatnya kepekaan terhadap radang saluran pernafasan, dapat terjadi setelah mendapat pajanan sebesar 100 $\mu \mathrm{g} / \mathrm{m} 3$ Percobaan pada manusia menyatakan bahwa kadar NO2 sebesar $250 \mu \mathrm{g} / \mathrm{m} 3$ dan $500 \mu \mathrm{g} / \mathrm{m} 3$ dapat mengganggu fungsi saluran pernafasan pada penderita asma dan orang sehat. 


\section{f. Timbal}

Timbal ditambahkan sebagai bahan aditif pada bensin dalam bentuk timbal organik (tetraetil-Pb atau tetrametil-Pb). Pada pembakaran bensin, timbal organik ini berubah bentuk menjadi timbal anorganik. Timbal yang dikeluarkan sebagai gas buang kendaraan bermotor merupakan partikel-partikel yang berukuran sekitar $0,01 \mu \mathrm{m}$. Partikelpartikel ini akan bergabung satu sama lain membentuk ukuran yang lebih besar, dan keluar sebagai gas buang atau mengendap pada knalpot. Pengaruh $\mathrm{Pb}$ pada kesehatan yang terutama adalah pada sintesa haemoglobin dan sistem pada syaraf pusat maupun syaraf tepi. Pengaruh pada sistem pembentukkan $\mathrm{Hb}$ darah yang dapat menyebabkan anemia, ditemukan pada kadar $\mathrm{Pb}$-darah kelompok dewasa 60-80 $\mathrm{gg} / 100 \mathrm{ml}$ dan kelompok anak > $40 \mu \mathrm{g} / 100 \mathrm{ml}$. Pada kadar $\mathrm{Pb}$-darah kelompok dewasa sekitar $40 \mu \mathrm{g} / 100 \mathrm{ml}$ diamati telah ada gangguan terhadap sintesa $\mathrm{Hb}$, seperti meningkatnya ekskresi asam aminolevulinat (ALA). Pengaruh pada enzim §-ALAD dapat diamati pada kadar $\mathrm{Pb}$-darah sekitar $10 \mu \mathrm{g} / 100 \mathrm{ml}$. Akumulasi protoporfirin dalam eritrosit (FEP) yang merupakan akibat dari terhambatnya aktivitas enzim ferrochelatase, dapat terlihat pada wanita dengan kadar $\mathrm{Pb}$-darah 20-30 $\mu \mathrm{g} / 100 \mathrm{ml}$, pada pria dengan kadar 25-35 $\mu \mathrm{g} / 100 \mathrm{ml}$, dan pada anak dengan kadar $>15 \mu \mathrm{g} / 100 \mathrm{ml}$. Pengaruh $\mathrm{Pb}$ terhadap hambatan aktivitas enzim ALAD tidak menyatakan adanya keracunan yang membahayakan, tetapi dapat menunjukkan adanya pajanan $\mathrm{Pb}$ terhadap tubuh. Meningkatnya ekskresi ALA dan akumulasi FEP adalam urin mencerminkan adanya kerusakan fungsi fisiologi yang pada akhirnya dapat merusak fungsi metokhondrial. Pengaruh pada syaraf otak anak diamati pada kadar $60 \mu \mathrm{g} / 100 \mathrm{ml}$, yang dapat menyebabkan gangguan pada perkembangan mental anak. Penelitian pada pengaruh $\mathrm{Pb}$ yang dikaitkan IQ anak telah banyak dilakukan tetapi hasilnya belum konsisten. Sistem syaraf pusat anak lebih peka dibandingkan dengan orang dewasa. Gangguan terhadap fungsi syaraf orang dewasa berdasarkan uji psikologi diamati pada kadar $\mathrm{Pb}$ darah $50 \mu \mathrm{g} / 100 \mathrm{ml}$. Sedangkan gangguan sistem syaraf tepi diamati pada kadar $\mathrm{Pb}$ darah 30 $\mu \mathrm{g} / 100 \mathrm{ml}$. Timbal dapat menembus plasenta, karena perkembangan otak peka terhadap logam ini, maka janinlah yang terutama mendapat resiko.

\section{Kondisi Udara di Provinsi Bali}

Provinsi Bali adalah sebuah kota kecil dengan aktivitas yang sangat padat. Kota ini terus bergerak sepanjang hari, selain sebagai pusat pemerintahan, Provinsi Bali juga merupakan pusat perdagangan, kesehatan dan pendidikan. Provinsi Bali memiliki luas $5.633 \mathrm{~km}^{2}$ dengan sembilan kabupaten yaitu Kota Denpasar, Badung, Tabanan, Buleleng, Jembrana, Klungkung, Bangli, Gianyar dan Karangasem.

Ditinjau dari sumbernya, maka pencemaran udara di Provinsi Bali sebagian besar bersumber dari sarana transportasi darat antara lain:

1. Meningkatnya jumlah kendaraan bermotor dari hari ke hari tidak seimbang dengan pertambahan panjang jalan dan perbaikan kondisi jalan, sehingga terjadi peningkatan jumlah dan kepadatan total kendaraan bermotor pada suatu area tertentu,

2. Meningkatnya laju emisi pencemar dari setiap kendaraan bermotor untuk setiap kilometer jalan yang ditempuh karena macetnya jalanan,

3. Tingginya biaya pemeliharaan dan perawatan kendaraan bermotor sehingga kendaraan tidak dirawat secara teratur,

4. Pembakaran bahan bakar minyak yang tidak sempurna karena mesinmesin kendaraan bermotor yang sudah tua,

5. Kurangnya jalur hijau dengan tanaman yang dapat mengabsorpsi bahan pencemar,

6. Terbatasnya dana untuk melakukan upaya pengawasan, pemantauan, pengujian kualitas udara dan sosialisasi kepada masyarakat, 
7. Pengaturan parkir kendaraan yang kurang optimal (SLHD Provinsi Bali, 2008)

Bila dilihat dari sumber pencemarnya, maka pencemaran udara di Provinsi Bali sebagian besar disebabkan oleh kendaraan bermotor, dimana kendaraan bermotor terus mengalami peningkatan. Pada tahun 2015, jumlah kendaraan bermotor di Provinsi Bali sebanyak 3.505.984 dan terus bertambah hingga mencapai 3.907.094 unit pada tahun 2018 (BPS, 2018). Peraturan Gubernur Nomor 8 Tahun
2007 tentang Baku Mutu Lingkungan
Hidup dan Kriteria Baru Kerusakan
Lingkungan Hidup
Dalam rangka menjaga kualitas lingkungan hidup di Provinsi Bali, Gubernur Bali telah menetapkan Peraturan Gubernur Nomor 8 Tahun 2007 sebagai acuan dalam pemeliharaan lingkungan hidup di Bali. Dalam Lampiran Peraturan Gubernur ini, terdapat ambang batas kandungan emisi gas buang kendaraan yang dijadikan acuan dalam jurnal ini. Ambang batas emisi gas buang tersebut dapat dilihat dalam tabel berikut:

Tabel 4. Ambang batas kandungan gas buang kendaraan yang diijinkan

\begin{tabular}{lll} 
No & \multicolumn{1}{c}{ Gas } & $\begin{array}{l}\text { Ambang batas } \\
\left(\mu \mathrm{g} / \mathrm{m}^{3}\right)\end{array}$ \\
1 & Sulfur dioksida & 900 \\
2 & Nitrogen dioksida & 400 \\
3 & Karbon monoksida & 30.000 \\
4 & Timbal & 2 \\
5 & $\mathrm{PM}_{2.5}$ & 15 \\
6 & $\mathrm{PM}_{10}$ & 150
\end{tabular}

Sumber: Pemerintah Provinsi Bali

\section{Dasar Hukum Yang Mengatur Tentang Pencemaran Udara dan Emisi Gas Buang Kendaraan}

Ada beberapa peraturan yang dibuat oleh Pemerintah untuk mengurangi dampak yang ditimbulkan oleh emisi gas buang kendaraan, antara lain:

1. Keputusan Menteri Negara Lingkungan Hidup Nomor 35 Tahun 1993 tentang Ambang Batas Emisi Gas Buang Kendaraan
Dalam Keputusan Menteri ini, ada beberapa hal penting yang menyangkut emisi gas buang kendaraan antara lain:

a. Ambang Batas Emisi Gas Buang Kendaraan Bermotor adalah batas maksimum zat atau bahan pencemar yang boleh dikeluarkan langsung dari pipa gas buang kendaraan bermotor;

b. Kandungan $\mathrm{CO}$ (karbon monoksida) dan $\mathrm{HC}$ (hidro karbon) dan ketebalan asap pada pancaran gas buang:

- Sepeda motor 2 (dua) langkah dengan bahan bakar bensin dengan bilangan oktana 387 ditentukan maksimum $4,5 \%$ untuk CO dan 3.000 ppm untuk HC;

- Sepeda motor 4 (empat) langkah dengan bahan bakar bensin dengan bilangan oktana 387 ditentukan maksimum 4,5\% untuk $\mathrm{CO}$ dan 2.400 ppm untuk HC;

- Kendaraan bermotor selain sepeda motor 2 (dua) langkah dengan bahan bakar bensin dengan bilangan oktana 387 ditentukan maksimum 4,5\% untuk CO dan 1.200 ppm untuk HC;

- Kendaraan bermotor selain sepeda motor 2 (dua) langkah dengan bahan bakar solar disel dengan bilangan setana ${ }^{3} 45$ ditentukan maksimum ekivalen $50 \%$ Bosch pada diameter 102 $\mathrm{mm}$ atau $25 \%$ opasiti untuk ketebalan asap.

c. Kandungan $\mathrm{CO}$ dan $\mathrm{HC}$ sebagaimana dimaksud diatas diukur pada kondisi percepatan bebas (idling).

d. Ambang Batas Emisi Gas Buang Kendaraan Bermotor ditinjau kembali sekurang-kurangnya dalam 5 (lima) tahun sekali.

2. Undang Undang No. 23 tahun 1997 tentang Pengelolaan Lingkungan Hidup. Undang Undang ini dijadikan sebagai dasar untuk perlindungan terhadap lingkungan. Hal-hal penting yang terkandung didalamnya antara lain bahwa setiap orang berhak untuk mendapatkan lingkungan hidup yang baik dan sehat, berhak untuk memperoleh informasi tentang lingkungan hidup, berkewajiban untuk mengelola lingkungan hidup sesuai dengan kebijakan yang terpadu untuk pengelolaan lingkungan hidup serta larangan bagi setiap orang atau 
kegiatan untuk melampaui baku mutu lingkungan.

3. Peraturan Pemerintah tahun 1999 tentang Pengendalian Pencemaran Udara

$\begin{aligned} & \text { Peraturan Pemerintah ini } \\ & \text { khusus mecara } \\ & \text { perlindungan kualitas }\end{aligned}$ udara
berdasarkan baku mutu udara
ambien, baku mutu emisi untuk
kegiatan industri dan kendaraan,
serta indeks standar pencemaran
udara (ISPU).
Undang Undang No 22 tahun 2001

Undang Undang No 22
tentang Minyak dan Gas

Undang-undang ini menjadi dasar hukum yang sangat penting bagi penyediaan bahan bakar yang lebih bersih. Salah satu aspek dari undang-undang ini yang terkait dengan pengendalian pencemaran udara adalah tugas pemerintah dalam penyusunan spesifikasi bahan bakar dan terbukanya bisnis bahan bakar untuk perusahaan di luar Pertamina untuk memproduksi dan mendistribusikan bahan bakar. Terbukanya pasar ini dan dikombinasikan dengan penentuan spesifikasi bahan bakar dapat mempercepat penyediaan bahan bakar yang lebih bersih, sehingga penggunaan teknologi kendaraan yang lebih modern yang dapat menurunkan emisi kendaraan dengan sangat signifikan dapat dilakukan.

\section{PEMBAHASAN}

Berdasarkan atas Laporan Status Lingkungan Hidup Provinsi Bali yang diterbitkan pada tahun 2015, polutan yang diteliti antara lain belerang dioksida $\left(\mathrm{SO}_{2}\right)$, nitrogen dioksida $\left(\mathrm{NO}_{2}\right)$, karbon monoksida (CO), Timbal $(\mathrm{Pb})$, dan debu $\left(\mathrm{PM}_{10}\right.$ dan $\mathrm{PM}_{2.5}$ ). Pengambilan sampel udara dilakukan 4 tempat yang dianggap mewakili kondisi udara ambien di Provinsi Bali yaitu terminal, lalu lintas padat, pemukiman padat dan pelabuhan.

\section{Belerang Dioksida $\left(\mathrm{SO}_{2}\right)$}

Dari hasil pengukuran sampel udara diperoleh data kandungan $\mathrm{SO}_{2}$ seperti dalam tabel berikut:

Tabel 5. Kandungan $\mathrm{SO}_{2}$ di Provinsi Bali

$\begin{array}{lll}\text { No } & \text { Kabupaten } & \mathrm{SO} 2 \\ & & \left(\mu \mathrm{g} / \mathrm{m}^{3}\right) \\ 1 & \text { Karangasem } & 153.59\end{array}$

$\begin{array}{lll}2 & \text { Klungkung } & 243.48 \\ 3 & \text { Bangli } & 210.48 \\ 4 & \text { Gianyar } & 284.45 \\ 5 & \text { Denpasar } & 270.21 \\ 6 & \text { Badung } & 315.26 \\ 7 & \text { Tabanan } & 193.73 \\ 8 & \text { Buleleng } & 249.14 \\ 9 & \text { Jembrana } & 362.32 \\ \text { Rata-rata } & 253.63\end{array}$

Sumber: SLHD Prov. Bali, 2015

Dari data dalam tabel 5 diatas dapat dilihat bahwa kandungan $\mathrm{SO}_{2}$ rata-rata di Provinsi Bali sebesar $253.63 \mu \mathrm{gg} / \mathrm{m}^{3}$. Nilai ini termasuk dibawah batas ambang sesuai dengan Peraturan Gubernur Bali Nomor 8 tahun 2007 dengan batas atas sebesar 900 $\mu \mathrm{g} / \mathrm{m}^{3}$. Hal ini menunjukkan bahwa rata-rata kandungan $\mathrm{SO}_{2}$ di Provinsi Bali masih dibawah batas atas yang diijinkan. Bahkan, kandungan SO2 tertinggi yang berada di Kabupaten Jembranapun masih di bawah ambang batas yang diijinkan.

\section{Nitrogen dioksida $\left(\mathrm{NO}_{2}\right)$}

Pengambilan sampel dilakukan di tempat yang sama dengan pengambilan sampel belerang dioksida sehingga diharapkan kondisi sampel sama dengan belerang dioksida. Dari hasil pengukuran, kandungan Nitrogen dioksida yang diperoleh dapat dilihat pada tabel 6 berikut:

\begin{tabular}{clc}
\multicolumn{3}{c}{ Tabel 6. Kandungan $\mathrm{NO}_{2}$ di } \\
No & $\begin{array}{c}\text { Provinsi Bali } \\
\mathrm{NO} 2 \\
\left(\mu \mathrm{g} / \mathrm{m}^{3}\right)\end{array}$ \\
1 & Karangaten & 40.68 \\
2 & Klungkung & 39.65 \\
3 & Bangli & 34.29 \\
4 & Gianyar & 61.30 \\
5 & Denpasar & 70.82 \\
6 & Badung & 98.83 \\
7 & Tabanan & 50.58 \\
8 & Buleleng & 23.98 \\
9 & Jembrana & 40.42 \\
Rata-rata & 51,17
\end{tabular}

Sumber: SLHD Prov. Bali, 2015

Dari tabel 6 diatas dapat dilihat bahwa kandungan gas Nitrogen dioksida rata-rata di Provinsi Bali sebesar 51,17 $\mu \mathrm{g} / \mathrm{m}^{3}$. Nilai ini berada dibawah ambang batas yang diijinkan oleh Peraturan Gubernur Bali Nomor 8 Tahun 2007 yaitu sebesar $400 \mu \mathrm{g} / \mathrm{m}^{3}$.

\section{Karbon Monoksida (CO)}


Karbon Monoksida adalah salah satu gas yang paling membahayakan kesehatan manusia bila terpapar dalam jumlah yang berlebihan. Berdasarkan sampel yang diambil, diperoleh data sebagai berikut:

Tabel 7. Kandungan CO di Provinsi Bali

$\begin{array}{lll}\text { No } & \text { Kabupaten } & \mathrm{CO}(\mu \mathrm{g} / \mathrm{m}) \\ & \text { Karangasem } & 421.40 \\ 2 & \text { Klungkung } & 717.46 \\ 3 & \text { Bangli } & 589.59 \\ 4 & \text { Gianyar } & 998.26 \\ 5 & \text { Denpasar } & 1245.91 \\ 6 & \text { Badung } & 952.23 \\ 7 & \text { Tabanan } & 859.61 \\ 8 & \text { Buleleng } & 929.33 \\ 9 & \text { Jembrana } & 851.08 \\ \text { Rata-rata } & 818.32\end{array}$

Sumber: SLHD Prov. Bali, 2015

Kandungan $\mathrm{CO}$ yang diijinkan berdasarkan Peraturan Gubernur Nomor 8 Tahun 2007 sebesar $30.000 \mu \mathrm{g} / \mathrm{m}^{3}$. Sementara hasil pengukuran menunjukkan bahwa kandungan gas $\mathrm{CO}$ di Provinsi Bali ratarata sebesar $818 \mu \mathrm{g} / \mathrm{m}^{3}$. Meskipun masih jauh dari ambang batas, namun harus mulai dilakukan tindakan pencegahan agar kandungan gas $\mathrm{CO}$ tidak terus bertambah mengingat gas ini adalah salah satu gas rumah kaca yang sangat membahayakan lingkungan.

\section{Timbal $(\mathrm{Pb})$}

Timbal dihasilkan oleh pembakaran yang tidak sempurna oleh kendaraan bermotor. Timbal ini sangat membahayakan kesehatan karena termasuk dalam logam berat yang sangat sulit untuk dimetabolisme oleh tubuh bila sampai masuk ke dalam tubuh manusia. Dari hasil pengukuran diperoleh data sebagai berikut:

Tabel 8. Kandungan $\mathrm{Pb}$ di Provinsi Bali

$\begin{array}{lll}\text { No } & \text { Kabupaten } & \mathrm{Pb}( \\ & & \\ 1 & \text { Karangasem } & 0.49 \\ 2 & \text { Klungkung } & 0.50 \\ 3 & \text { Bangli } & 0.52 \\ 4 & \text { Gianyar } & 0.59 \\ 5 & \text { Denpasar } & 0.60 \\ 6 & \text { Badung } & 0.61 \\ 7 & \text { Tabanan } & 0.57 \\ 8 & \text { Buleleng } & 0.61 \\ 9 & \text { Jembrana } & 0.58\end{array}$

Rata-rata 0.56

Sumber: SLHD Prov. Bali, 2015

Dari Tabel 8 diatas, dapat diketahui bahwa rata-rata kandungan timbal dalam udara di Provinsi Bali sebesar $0.56 \mu \mathrm{g} / \mathrm{m}^{3}$. Berdasarkan baku mutu udara ambien yang telah ditetapkan maka nilai ini masih berada dibawah batas kandungan Timbal yang diijinkan yaitu sebesar $2 \mu \mathrm{g} / \mathrm{m}^{3}$.

5. Debu $\left(\mathrm{PM}_{10}\right.$ dan $\left.\mathrm{PM}_{2.5}\right)$

Particulate Matter adalah partikel kecil yang mampu merusak kesehatan manusia karena mampu masuk ke dalam pernafasan manusia. Dampak yang ditimbulkan oleh debu ini antara lain gangguan pada sistem pernafasan dan gangguan terhadap jarak pandang.

Dari pengukuran terhadap $\mathrm{PM}_{10}$ dan $\mathrm{PM}_{2.5}$ di Provinsi bali diperoleh data sebagai berikut:

Tabel 9. Kandungan $\mathrm{PM}_{10}$ dan $\mathrm{PM}_{2.5}$ di Provinsi Bali

$\begin{array}{llll}\text { No } & \text { Kabupaten } & \begin{array}{l}\mathrm{PM}_{2.5} \\ \left(\mu \mathrm{g} / \mathrm{m}^{3}\right)\end{array} & \begin{array}{l}\mathrm{PM}_{10} \\ \left(\mu \mathrm{g} / \mathrm{m}^{3}\right)\end{array} \\ 1 & \text { Karangasem } & 4.11 & 241.95 \\ 2 & \text { Klungkung } & 4.49 & 326.65 \\ 3 & \text { Bangli } & 2.68 & 213.70 \\ 4 & \text { Gianyar } & 3.60 & 243.35 \\ 5 & \text { Denpasar } & 3.61 & 277.02 \\ 6 & \text { Badung } & 4.03 & 320.28 \\ 7 & \text { Tabanan } & 3.44 & 270.55 \\ 8 & \text { Buleleng } & 3.40 & 280.90 \\ 9 & \text { Jembrana } & 4.06 & 304.07 \\ \text { Rata-rata } & 3.71 & 275.39\end{array}$

Sumber: SLHD Prov. Bali, 2015

Dari data diatas diketahui bahwa kandungan $\mathrm{PM}_{2.5}$ di Provinsi Bali sebesar $3.71 \mu \mathrm{g} / \mathrm{m}^{3}$. Nilai ini masih berada dibawah batas normal yang diijinkan yaitu $15 \mu \mathrm{g} / \mathrm{m}^{3}$. Sedangkan untuk $\mathrm{PM}_{10}$, nilai rata-ratanya adalah $275.39 \mu \mathrm{g} / \mathrm{m}^{3}$. Nilai ini berada di atas ambang batas yang diijinkan yaitu 150 $\mu \mathrm{g} / \mathrm{m}^{3}$. Nilai ini menunjukkan bahwa kandungan debu di Provinsi Bali sudah melewati ambang batas yang diijinkan sehingga perlu dilakukan langkah-langkah untuk menurunkan nilai $\mathrm{PM}_{10}$ ini.

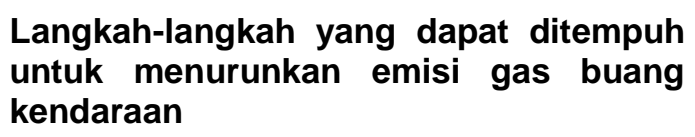


Dari hasil pengukuran kandungan gas buang kendaraan yang sudah dilakukan diatas, dapat dilihat bahwa sebagian besar kandungan gas buang kendaraan masih berada dibawah batasyang diijinkan kecuali $\mathrm{PM}_{10}$. Namun, sebaiknya Pemerintah Provinsi Bali mulai memikirkan dan mencari solusi agar nilainilai yang saat ini dihasilkan oleh transportasi ini tidak terus bertambah. Langkah-langkah yang bisa diambil antara lain:

1. Mengurangi jumlah kendaraan bermotor dengan menerapkan pajak progresif

2. Mengurangi jumlah kendaraan bermotor dengan mengefektifkan penggunaan angkutan umum

3. Memberlakukan rekayasa lalu lintas
4. Menambah jumlah taman kota ataupun hutan kota

\section{Daftar Pustaka}

Mukono, H.J. 1997. Pencemaran Udara dan Pengaruh Terhadap Gangguan Saluran Pernafasan. Surabaya. AUP.

Pemerintah Provinsi Bali. 2015. Status Lingkungan Hidup Provinsi Bali 2015. Bali.

Pemerintah Provinsi Bali. 2015. Status Lingkungan Hidup Provinsi Bali 2015. Bali.

Biro Pusat Statistik. 2018. Bali Dalam Angka 2018. Bali.

Fardiaz, Srikandi. 1992. Polusi Air dan Udara. Kanisius. Yogyakarta

Peraturan Pemerintah no. 41 tahun 1999 tentang Pengendalian Pencemaran Udara 